\title{
First branchial cleft anomaly
}

\author{
M. A. R. Al-FAllouji* \\ F.R.C.S. (Edin), F.R.C.S. (Glas), F.R.C.S.I. \\ M. F. BUTLER \\ F.R.C.S. (Eng) \\ Surgical Department, Isle of Thanet District Hospital, Margate Wing, St Peter's Road, Margate, Kent
}

\section{Summary}

A 15-year-old girl presented with a cystic swelling since birth behind the ramus of the right mandible and diagnosed clinically as a dermoid cyst. Surgical exploration, however, showed that it was closely related to the external auditory canal, with an extension running medially behind the parotid gland and ending in the bony middle ear. The facial nerve was closely related to the deep part of the cyst. Such an anatomical position indicates that this was a first branchial cleft anomaly. Surgical excision of the cyst was performed.

KEY WORDS: branchial cyst, branchial apparatus, anomalies.

\section{Introduction}

The usual congenital anomaly of the branchial apparatus is branchial cyst and fistula arising from the second branchial cleft and pouch (Patey, 1965). Much less common are derivatives of the first arch (Jones, 1969), from which cysts and fistulae may form (Patey, 1965).

In a review of 82 cases of branchiogenic anomalies, only one case was considered as of first cleft derivation (Ladd and Gross, 1938). In the Mayo Clinic series of 319 cases collected over 30 years, no first cleft anomaly was encountered (Neel and Pemberton, 1945). Byars and Anderson (1951) presented 3 cases of first branchial cleft anomalies. Wilson (1955) in a review of 86 cases of lateral cervical cysts and fistulae of developmental origin, collected during 20 years at the Middlesex Hospital, described the different courses of such fistulae and referred to cervico-aural fistulae as derivatives of the ectodermal part of the first cleft, of which he said that only 12 cases have been previously recorded. Patey (1965) mentioned 2 submandibular cysts of obscure origin in connection with first branchial cleft anomalies.

\footnotetext{
* Present address: Newmarket General Hospital, Newmarket. West Suffolk CB8 7JG.
}

In view of the extreme rarity of this developmental abnormality, it seems worthwhile to report this case.

\section{Case report}

A 15-year-old white girl presented with a rounded $(2.5 \mathrm{~cm}$ in diameter), painless deep cystic swelling behind the ramus of the right mandible and just below the pinna of the ear (Fig. 1). The overlying skin was freely mobile. The cyst was mainly a cosmetic problem with progressive enlargement since birth. She had had a stuffy nose with chronic nonproductive cough for many years.

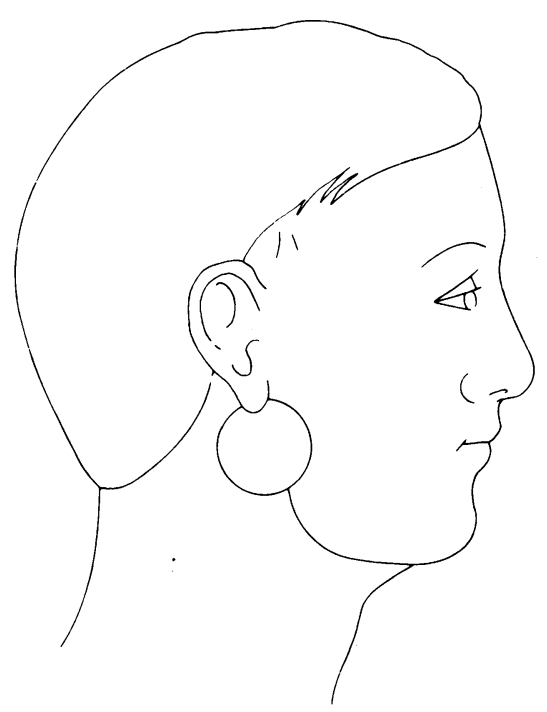

FIG. 1. The site of the 1st branchial cleft cyst (sinus).

The lesion was diagnosed clinically as a dermoid cyst. Surgical exploration under general anaesthesia, however, showed that it was closely adherent to the external auditory canal and intimately related to the back of the parotid gland. The deep extension ran 
medially behind the parotid gland ending on the bony auditory canal (middle ear) near the temporomandibular joint after passing dorso-laterally to the trunk of facial nerve (Fig. 2). A probe indicated a fistulous communication into the middle ear cavity.

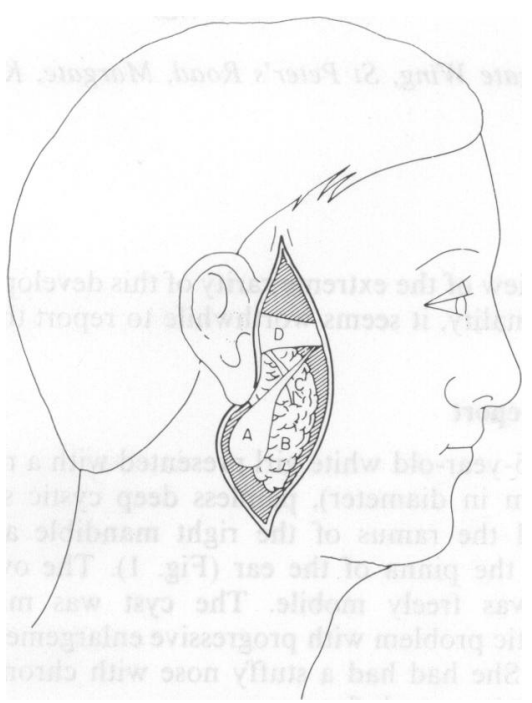

FIG. 2. The course of the Ist branchial cleft sinus (A), intimately related to the back of parotid gland (B), and its track is passing above the facial nerve (C) and ending on the auditory canal (D).

The cyst was successfully removed. It contained opalescent thick milky fluid and histology showed a sinus of unknown origin with lining partly fibrous and partly inflamed and surrounded by salivary and lymphadenoid tissues. The inflammatory changes were explicable on the basis of recurrent and chronic upper respiratory tract infection spreading into the cyst via the Eustachian tube and middle ear rendering the lining almost completely denuded.

The high cervical, suprahyoid, post-mandibular, juxta-auditory location with its course left no doubt that this was a first branchial cleft sinus. The patient was well when reviewed 4 months later. Her nasal stuffiness disappeared but her dry cough only partially improved.

\section{Embryology}

In a fetus approximately 30 days old, at least 4 well-developed grooves can be seen on the side of the neck (Bailey, 1933). These external branchial grooves or clefts have their internal counterparts, the pharyngeal sacs or pouches; thus each branchial arch consists of an ectodermal exterior, a mesenchymal core and an endodermal interior (Gray's Anatomy,
1973). The first branchial arch bifurcates into mandibular and maxillary processes.

The first pouch is the only pouch in which ectoderm and endoderm remain in any sort of contact (the tympanic membrane) and its external pharyngeal groove becomes deepened to form the external acoustic meatus while the endoderm is prolonged laterally via the auditory tube to form the middle ear and mastoid antrum (Last, 1978).

Though the second pouch gives a contribution to the middle ear (Last, 1978), the tympanic cavity (of the middle ear) is derived wholly from the first pouch (Gray's Anatomy, 1973) and the Eustachian tube represents the persistent first branchial cleft (Bailey, 1933).

During the 6th embryonic week, the second arch grows, overlapping the most caudal arches and grooves forming an ectodermal cervical sinus, persistence of which leads to the usual branchial cleft cyst or fistula opening into the fossa of Rosenmuller (Bailey, 1933) posterior to the faucial tonsil.

\section{Discussion}

The diagnosis of first branchial cleft anomaly rests in its high lateral cervical, suprahyoid site, especially. if there is a history of ear discharge without otitis media (Byars and Anderson, 1951). This could be confirmed by injection of colouring material to demonstrate the sinus or the cervical fistula (Wilson, 1955). Operatively, the diagnosis will be obvious by demonstrating the deep postmandibular, juxta-auditory location and the possible fistulous track with its peculiar relation both to the auditory canal and facial nerve (Wilson, 1955; Jones, 1969).

Cysts, if left, will not regress and may well become infected. They should be removed (Peter-Mills, 1978). Typically, the lining is stratified squamous epithelium, indicating its ectodermal origin (Byars and Anderson, 1951).

This typical lining is not a constant finding as many recurrent attacks of inflammation in the fistula will render the lining partially or completely denuded (Bailey, 1933) as the internal or external communication of a sinus opens the way for infection and the formation of an abscess (Jones, 1969).

Dissection and removal are more easily performed before infection has occurred, and surgery can be safely undertaken at any time after the age of 6 months (Jones, 1969). Surgical excision under general anaesthesia is the treatment of choice (Byars and Anderson, 1951). The incision should be made as for parotid exposure. The cyst lies in close contact to the external auditory canal. The deep extension of the cyst needs to be carefully dissected due to its relation to the facial nerve which should be preserved. Though the nerve-sinus relationship is variable 
(Jones, 1969), in our case the facial nerve trunk passed immediately behind and below the deep part of the cyst.

The fistula (if present) is preferably cannulated by a fine probe or ureteric catheter to see its course. A cuff of cartilage extending from the external auditory canal may be excised with the specimen (Byars and Anderson, 1951) but if the track ends on the bony canal (as in this case) it should be disconnected close to its origin if feasible. Communication with the middle ear is extremely rare; Hyndman and Light (1929) mentioned an unusual case reported by Vonberg in which the cervical sinus communicated with the middle ear. Probably our patient is the second to be reported.

\section{Acknowledgments}

We thank Dr M. D. Farley for his histology report and advice. Our appreciation to Mrs Price, Claire Grimsey and Mrs E. Hawley for their co-operation in the preparation of this paper.

\section{References}

BaILEY, H. (1933) The clinical aspects of branchial fistulae. British Journal of Surgery, XXI, 173.
ByARs, L.T. \& ANIterson, R. (1951) Anomalies of the first branchial cleft. Surgery, (ivnaecology and Ohstetrics, 93, 755.

GRAY's ANATOMY (1973) The branchial apparatus embryology. (Eds. R. Warwick and P.L. Williams), p. 116. Longman, (ireat Britain.

HYNIMAN, D.R. \& LI(iHT, G. (1929) The branchial apparatus. Archives of Surgery, 19, 410 .

JONES, P.G. (1969) Branchial sinuses and cysts. In: Operative Surgery (Head, Neck and Lymph Nodes) Vol. 6 (Eds. C. Rob and R. Smith) 2nd edn., p. 19. Butterworths, London.

LADD, W.E. \& GRoss, R.E. (1938) Congenital branchiogenic anomalies. American Journal of Surgery, 39, 234.

LAST, R.J. (1978) Early Embryology. Anatomy Regional and Applied. 6th edn., p. 41. Churchill Livingstone, Edinburgh, London and New York.

Neel, H.B. \& Pemberton, J. (1945) Lateral cervical cysts and fistulae. Surgery, 18, 267.

PateY, D.H. (1965) Cysts and tumours of the head and neck. In: Clinical Surgery-9 (Head and Neck) (Eds. C. Roo and R. Smith), p. 118, 120. Butterworths, London.

Peter-Mills, C. (1978) Surgical treatment of branchial cysts and sinuses. In: Operative Surgery (Nose and Throat) (Eds. C. Rob and R. Smith), Butterworths, London, Boston.

WILSON, C.P. (1955) Lateral cysts and fistulae of the neck of developmental origin. (Hunterian Lecture). Annals of the Royal College of Surgeons, England, 17, 6, 1.

(Accepted 28 October 1982) 